\title{
DFT-based QSAR studies and Molecular Docking of 1-Phenylcyclohexylamine Analogues as anticonvulsant of NMDA Receptor
}

\author{
Charif El M'barki, Mohamed Mazigh, Hanine Hadni and Menana Elhallaoui \\ Engineering Materials, Modeling and Environmental Laboratory, Faculty of Sciences of Dhar Elmehraz, \\ Sidi Mohammed Ben Abdellah University, B.P. 1796, Atlas, Fez, Morocco
}

\begin{abstract}
The phencyclidine (PCP) and their analogues have been reported to exhibit inhibitory activities toward the N-methyl-D-aspartate receptor (NMDAR). To discover the QSAR between structure of PCP derivatives and $\mathrm{Ki}$ activities we have used density functional theory (DFT) to generate quantum descriptors, multiple regression linear (MLR) method was applied to establish QSAR model, and an artificial neural network (ANN), considering the relevant descriptors obtained with the MLR method is explored, a correlation coefficient of $R_{\text {ANN }}=0.912$ was obtained with 6-4-1 ANN model. This model is tested by using a cross-validation method with the LOO procedure $\left(\mathrm{R}_{\mathrm{CV}}=0.841\right)$. To study the configuration impact on activity, we proceed to the Molecular Docking of four configurations, two configurations of compound have $(\mathrm{Ki}=502 \mathrm{nM})$ and two configurations of compound have $(\mathrm{Ki}=1200 \mathrm{nM})$. The phenyl group, when placed in an equatorial position in cis9e, a configuration of the less active compound, does not form $\pi$-sigma interaction. The superimposition of this configuration with trans7e reveals that the phenyl group of cis9e configuration is shifted from the binding site compared to trans7e which forms an interaction $\pi$-sigma throughout its phenyl group with ARG B: 894 . So, we could claim that the cis9e is the configuration adopted by compound having $(\mathrm{Ki}=502 \mathrm{nM})$.
\end{abstract}

Keywords: Inhibition activity; QSAR model; MLR; ANN; LOO; Docking.

\section{Introduction}

The NMDA receptor is involved in many neurological disease studies; which cause trouble in various types of learning and memory task $\mathrm{b}^{1-5}$. The NMDA receptor is a receptor-channels ${ }^{6}$; it is composed of two subunits NR1/NR2 or NR1/NR3 ${ }^{2,6-9}$, which have a variety of binding sites of synthetic non-competitive antagonist drugs such as phencyclidine (PCP), thienylcyclohexylpiperidine (TCP) and (+)-10,11Dihydro-5-methyl-5H dibenzo(a,d)cyclohepten-5,10diyldiammonium maleate (MK801) ${ }^{10,11}$.

Several attempts had been performed in the goal to understand the mechanism of the interaction mode of non-competitive antagonists with the NMDAR. Recently, a novel family of allosteric modulators was discovered and helped to distinguish between NMDARs depending upon their GluN2 subunit composition ${ }^{12-16}$. To date, however, the binding site and mechanisms of action of these compounds remain unknown. This is partly because of the lack of knowledge about the full-length NMDAR structure that is comprised of unique, multi-domain patterns of interaction, which was not elucidated until recently by X-ray crystallography. Previous studies of Costa and collaborators ${ }^{13-15,17}$ demonstrate that the compounds are not channeled blockers, do not bind at the glutamate or glycine binding sites, and do not require the N-terminal domain (NTD) for their activity. Despite the low affinity exhibited by the modulators at this point, their novelty in activity pattern, chemical structure, and mechanism of action warrant further investigation of their binding site to contribute to the further development of high-affinity compounds. In an antecedent paper in which we have proposed an electrostatic and geometrical pharmacophore based on superimposition of PCP, ketamine dexoxadrol and other non-competitive antagonists with the two configurations of MK801, we had presented a description of interaction mode using molecular modeling techniques ${ }^{18}$.

Always, to more understand about the mode of interaction and to improve the activity at this receptor, in this work we propose a predictive QSAR model based on data analysis methods (multiple linear regression-MLR-analysis and artificial neural network-ANN), which is validated with crossvalidation method-CV. On the other hand, we have

Received August 5, 2019

Accepted September 9, 2019

Published December 12, 2019 
proceeded to molecular docking of some compounds with the NMDA receptor.

\section{Methods and materials}

2.1. Multiple regression linear (MLR) and artificial neural network (NN)

To establish a structure-activity relationship for noncompetitive antagonists of the NMDA receptor, our study is realized in a series of $38 \mathrm{PCP}$ derivatives that have been analyzed and tested for their binding affinities to the PCP binding sites in rat brain membranes labeled with $\left[{ }^{3} \mathrm{H}\right]$-1-[1-(2thienyl)cyclohexyl]piperidine $\left({ }^{3} \mathrm{H}-\mathrm{TCP}\right){ }^{19}$. In this work, the Ki activity is expressed in $\mathrm{nM}^{19}$, and it is presented in a logarithmic scale (pKi). Table 1 shows the chemical structures of the studied compounds, their observed $\mathrm{pKi}$ values ( $\mathrm{pKi}_{\mathrm{obs}}$ ) and the MLR, ANN and $\mathrm{CV}$ predicted ones, respectively $\mathrm{pKi} \mathrm{R}_{\mathrm{RLM}} ; \mathrm{pKi}_{\mathrm{ANN}}$ and $\mathrm{pKi}_{\mathrm{CV}}$.

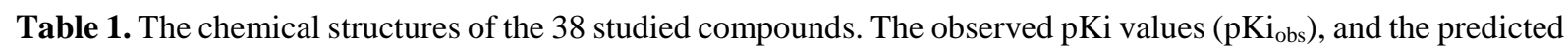
$\mathrm{pKi}\left(\mathrm{pKi} \mathrm{RLM}_{\mathrm{RL}}\right.$ pKi $\mathrm{ANN}_{\mathrm{ANN}}$ and $\left.\mathrm{pKi} \mathrm{CV}_{\mathrm{C}}\right)$ calculated using the MLR, ANN and CV methods, respectively.

\begin{tabular}{|c|c|c|c|c|c|c|}
\hline Compound & Structure & Ki.nM & $\mathbf{p K \mathbf { i } _ { \text { obs } }}$ & $\mathbf{p K \mathbf { i } _ { \text { MLR } }}$ & $\mathbf{p K i _ { \text { ANN } }}$ & $\mathbf{p K i}_{\mathbf{C V}}$ \\
\hline 1 & & 70 & -1.8451 & -1.97992 & -1.8527 & -1.784 \\
\hline 2 & & 527 & -2.7218 & $\mathbf{- 3 . 4 3 9 7 5}$ & -2.7863 & -2.9897 \\
\hline 3 & & 347 & -2.54033 & -3.03868 & -2.6528 & -2.9897 \\
\hline 4 & & 722 & -2.85854 & -2.58646 & -2.977 & -2.4348 \\
\hline 5 & & 2000 & -3.30103 & -3.12298 & -3.2767 & -2.8896 \\
\hline 6 & & 1600 & -3.20412 & -3.07526 & -3.5552 & -3.1673 \\
\hline 7 & & 502 & -2.7007 & -3.20267 & -3.0391 & -3.2692 \\
\hline
\end{tabular}




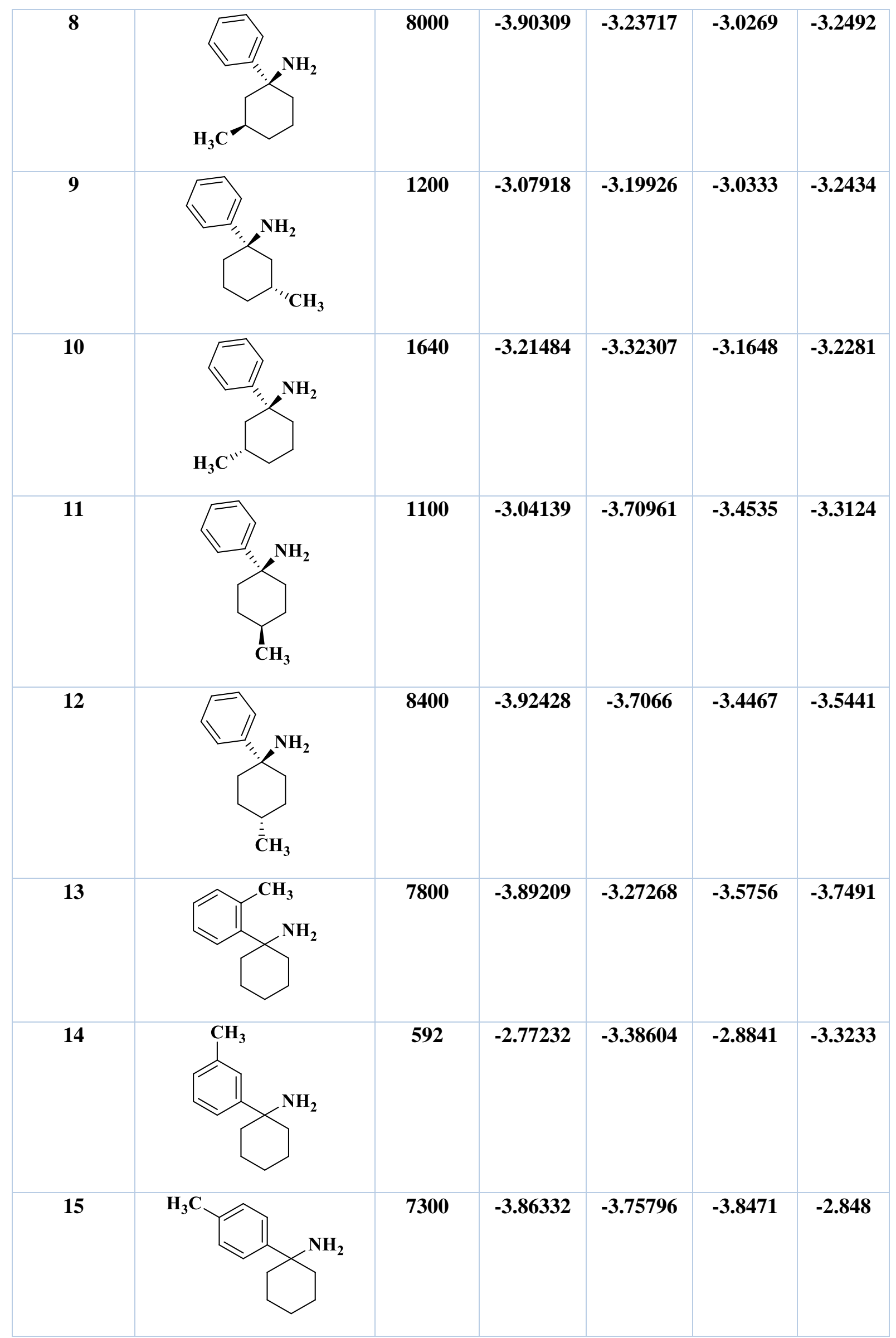




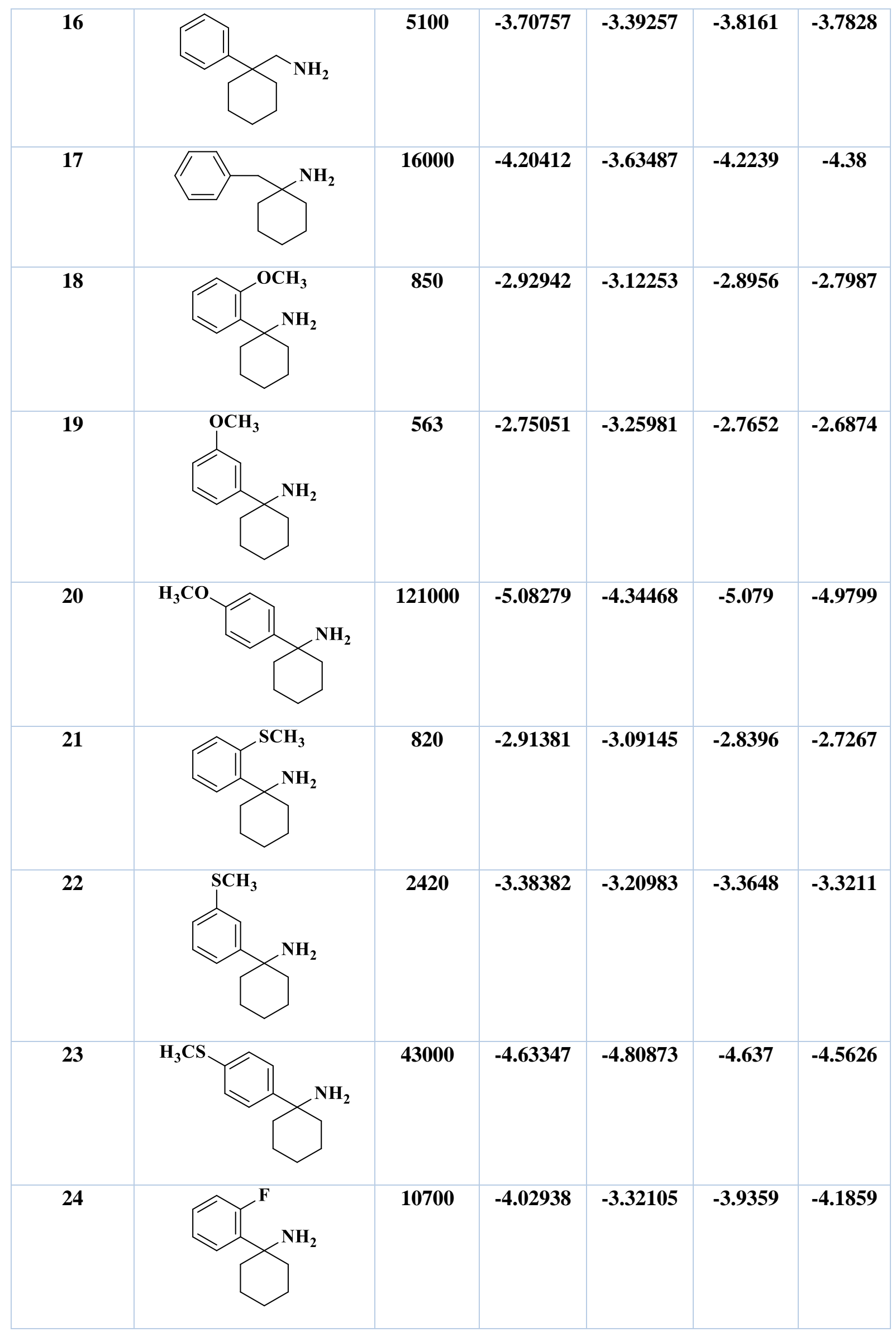




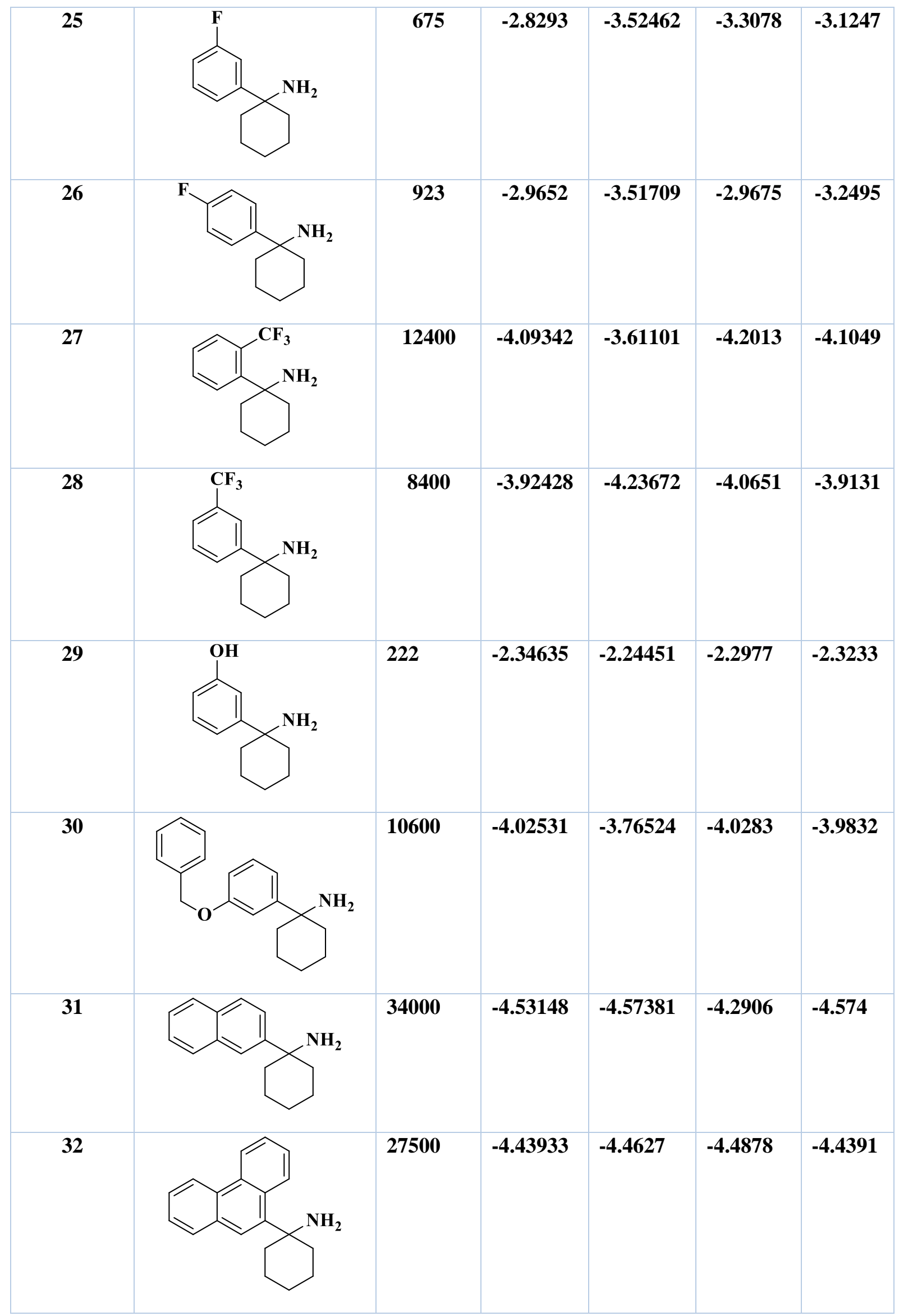




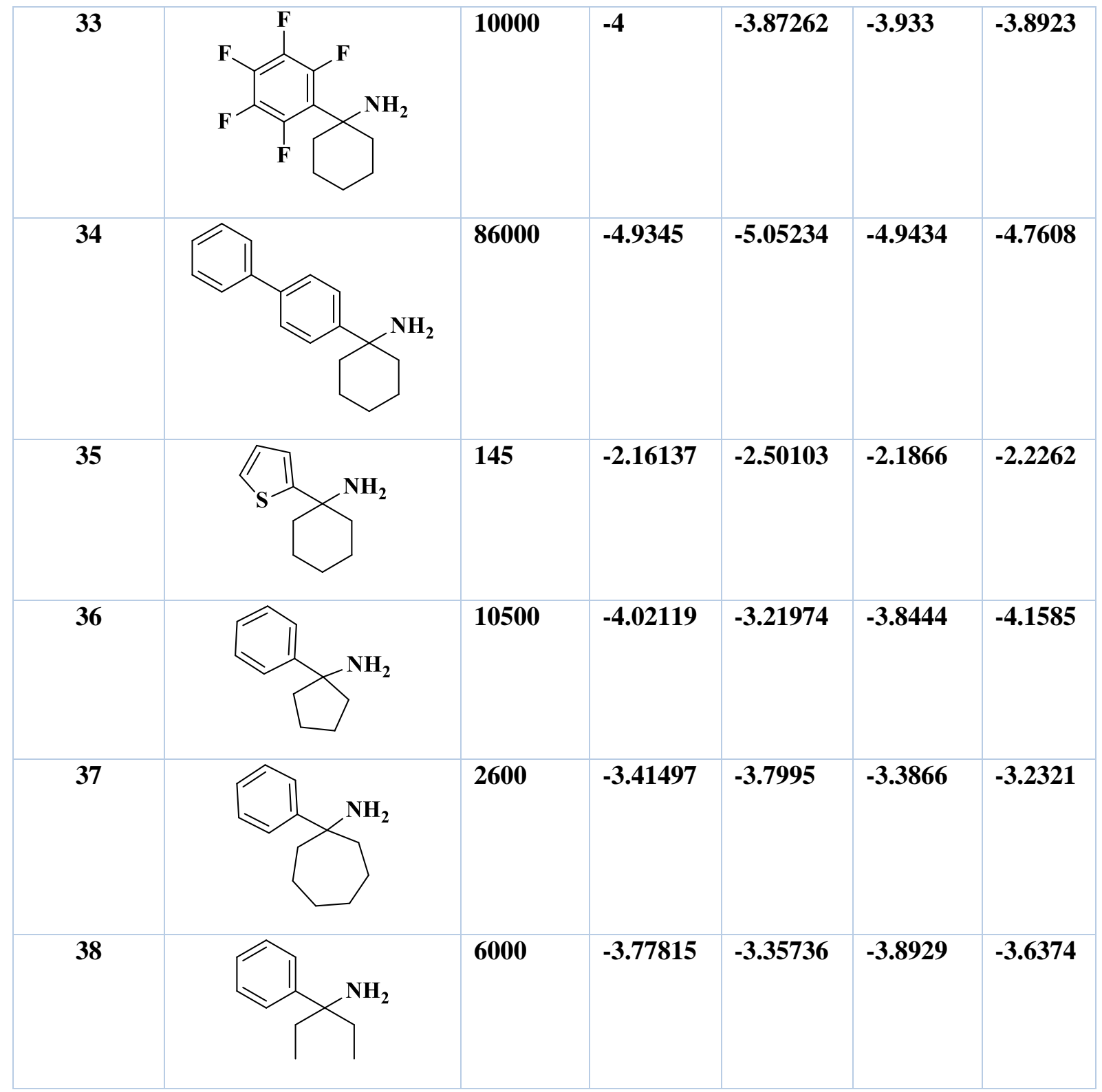

The electronic descriptors were obtained from quantum chemical calculations. So, all compounds were fully optimized with the density functional theory (DFT)/B3LYP ${ }^{20-22}$, combined with the 6-31G* basis set. All the calculations were performed using the Gaussian 03 software. The rest of the representative descriptors were calculated with the MM2 method using ChemBio3D Ultra (version 13.0) and ACD Lab ${ }^{23}$. The total descriptors chosen to construct the QSAR model are summarized in Table 2.

Table 2. The Computed descriptors, constituting the data table to construct the QSAR model.

\begin{tabular}{|l|l|l|l|}
\hline Categoryof descriptors & Description & Notation & Method \\
\hline Electronic & Dipole moment & $\mu$ & \\
& Electrophilicity Index & EI & DFT \\
& Total energy & E & \\
Electronic affinity & A & \\
Thermodynamic & Dipole Length & DL & MM2 \\
& Index of refraction & $\Omega$ & \\
& Polarisability & & \\
& & & \\
\hline
\end{tabular}




\begin{tabular}{|l|l|l|l|}
\hline & Molar refractivity & MR & MM2 \\
Henry's law cte & H & \\
& Sum of Degrees & SD & \\
& Sum of valence degrees & SOV & \multirow{2}{*}{ MM2 } \\
& Cluster Count & ClsC & \\
& Diameter & De & \\
& Density & pKa & O \\
& pKa & LogP & \\
& Ovality & Log P & \\
\hline
\end{tabular}

The different QSAR techniques and methods applied in this work are detailed in our previous paper ${ }^{24,25}$.

\subsection{Molecular Docking}

Molecular docking is performed with AutoDockTools 26,27 . The native structure of the NMDA receptor was retrieved from the protein data bank (PDB code: 2HQW, resolution: $1.9 \AA^{28}$ ). Our ligands are built and optimized with chemBio3D Ultra 13.0 software, and the docked conformations were viewed using Discovery Studio 4.1 software package ${ }^{29}$. The docking process parameters are adjusted as follows: the Grid size set is $100 \times 40 \times 40$ related to $\mathrm{XYZ}$ dimension, with grid spacing of $0.375 \AA$, the center grid box is of $23 \AA,-25 \AA, 17 \AA$, the number of Genetic Algorithm run $=5$, the population size $=150$, the maximum number of evaluations $=2.5$ million, the maximum number of generations $=27000$ parameters . The binding mode analysis is performed with the complex (ligand + receptor) having the lowest energy ${ }^{30}$.

To study the configuration impact on activity, two molecules, compound $7(\mathrm{Ki}=502 \mathrm{nM})$ and compound<smiles>CC1CCCC(N)(c2ccccc2)C1</smiles>

$\operatorname{tans} 7 \mathbf{a}$<smiles>CC1CCCC(N)(c2ccccc2)C1</smiles>

cis 9a
$9(\mathrm{Ki}=1200 \mathrm{nM}$ almost three-fold higher than that of compound 7) were submitted to molecular docking. Compounds 7 and 9, as it is shown in Figure 1, have the same chemical structure but have different configurations of asymmetric carbons 1 and 3 .<smiles>C[C@H]1CCC[C@](N)(c2ccccc2)C1</smiles>

Compound 7 (1R, 3S) $\mathrm{Ki}=\mathbf{5 0 2} \mathrm{nM}$<smiles>C[C@@H]1CCC[C@](N)(c2ccccc2)C1</smiles>

Compound 9 (1R, 3R) $\mathrm{Ki}=1200 \mathrm{nM}$
Figure 1. Chemical structures of compound 7 and 9

The configurational analysis of compounds 7 and 9 showed that each molecule is presented in two forms (Figure 2), so that the group phenyl could adopt an axial position (trans7a, cis9a) or an equatorial position (trans7e, cis9e).

Figure 2. The 4 configurations of compounds 7 and 9

\section{Results and Discussion}

\subsection{Multiple Regression Linear}

To quantify the relationship of molecules structure of non-competitive antagonists of the NMDA receptorrelated to their $\mathrm{Ki}$ activities, $38 \mathrm{PCP}$ derivatives have been submitted to the MLR method. This method uses the correlation coefficient $(\mathrm{R})$, the determination coefficient $\left(\mathrm{R}^{2}\right)$ and $t$-value values to select the best model. Good results are obtained with 6 descriptors: Somme of degrees (SD), diameter (D), pKa, Dipole moment $(\mu)$, Density (De) and Electrofilicity index (Ei).

The best model is represented by the following equation:

$$
\begin{gathered}
p K \boldsymbol{i}=13.281+0.167 S D-0.536 D-0.986 \boldsymbol{p K a}+\mathbf{0 . 5 8 0} \boldsymbol{\mu}-\mathbf{5 . 2 1 9} \boldsymbol{D} \boldsymbol{e}-\mathbf{2 . 6 2 4} \boldsymbol{E} \boldsymbol{i} \\
\mathrm{R}=0.825 \quad \mathrm{R}^{2}=0.681 \quad \mathrm{~S}=0.478
\end{gathered}
$$


The selected descriptors related to their coefficients

with their standard errors and the t-values are shown in Figure 2.

Table 2. the selected descriptors related to their coefficients with their standard errors and the t-values.

\begin{tabular}{|l|c|c|c|}
\hline Descriptor & Coefficient & standard Error & t-values \\
\hline SD & 0.167 & 0.043 & 3.869 \\
\hline $\mathrm{D}$ & -0.536 & 0.124 & -4.325 \\
\hline $\mathrm{pKa}$ & -0.986 & 0.345 & -2.860 \\
\hline$\mu$ & 0.580 & 0.240 & 2.421 \\
\hline $\mathrm{De}$ & -5.624 & 2.391 & -2.183 \\
\hline $\mathrm{Ei}$ & -2.624 & 0.504 & -5.209 \\
\hline
\end{tabular}

The MLR model shows an important contribution to the electronic and topological descriptors. We note the high contribution of the Dipole moment $(\boldsymbol{\mu})$, Electrofilicity index (Ei).
The predicted activities values ( $\left.\mathrm{pKi} \mathrm{i}_{\mathrm{RLM}}\right)$ calculated from the MLR model and those observed ( $\mathrm{pKi}_{\text {obs }}$ ) are presented in Table 1 . The correlation between $p \mathrm{pi}_{\text {RLM }}$ and $\mathrm{pKi}_{\text {obs }}$ is illustrated in Figure 3.

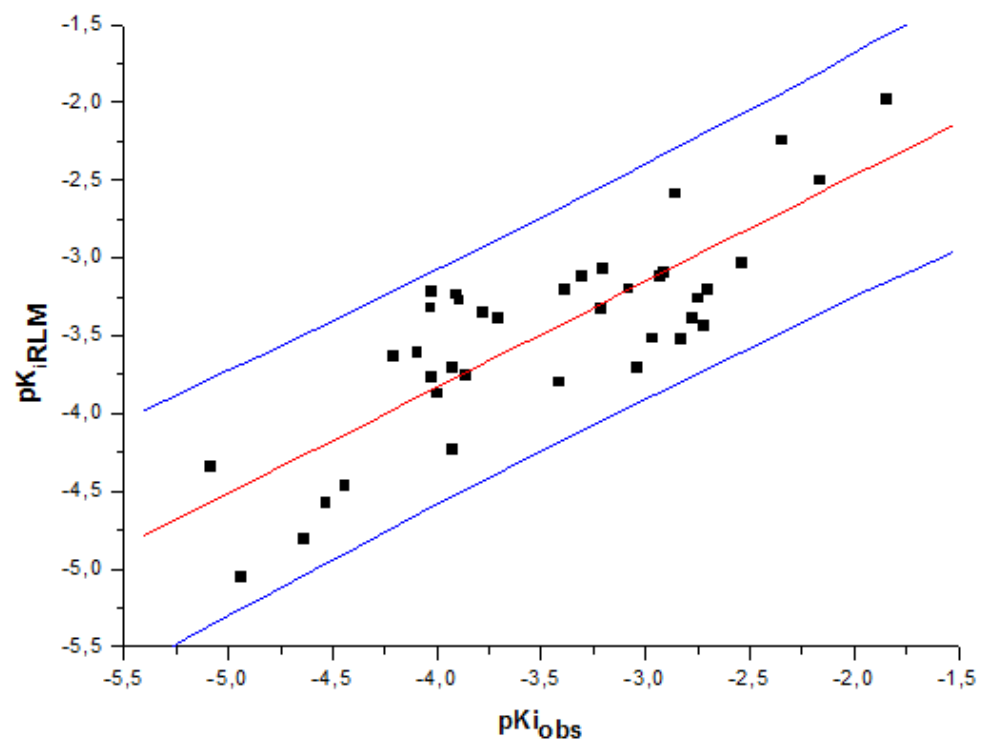

Figure 3. The correlation between $\mathrm{pKi} \mathrm{R}_{\mathrm{RL}}$ and $\mathrm{pKi} \mathrm{i}_{\mathrm{obs}}$

The selected descriptors by MLR are used as the input layer parameters in the Neural Network (NN).

\subsection{Neural network $(\mathrm{NN})$}

To improve the QSAR model, we have proceeded to a non-linear method, so the $\mathrm{NN}$ is a suitable technique to implement this task. The data table comprising the six descriptors selected by MLR is submitted to three layers ANN. So, the network input layer is composed of six neurons; the output layer is a linear neuron that represents the $\mathrm{pKi}_{\text {obs }}$ activity, the hidden layer has been defined by

$\rho=\frac{\text { number of weight }}{\text { number of connection }}$ which should have a value between 1 and 3 31. Therefore, for a network configuration (6-4-1) the number of weight is 38 , so $\rho=1.15$, which leads to an acceptable network.

The $\mathrm{pKi}_{\mathrm{ANN}}$ values predicted by the neural network are shown in Table 1, and the correlation between $\mathrm{pKi}_{\mathrm{obs}}$ and $\mathrm{pKi} \mathrm{inN}_{\mathrm{ANN}}$ is illustrated in Figure 4. 


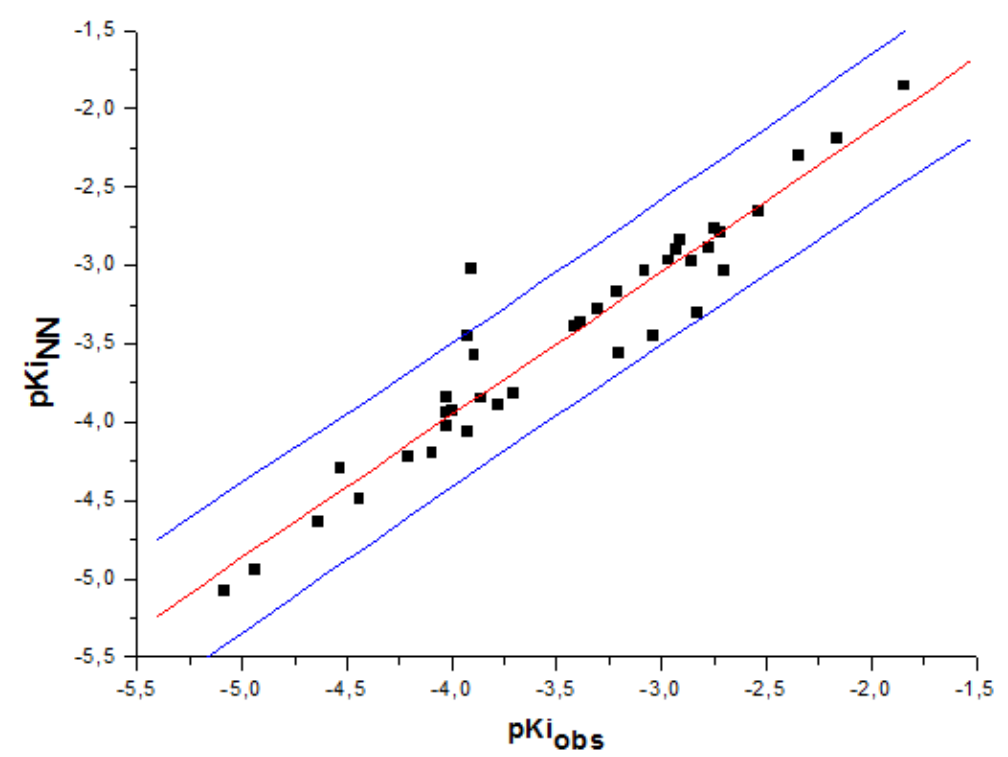

Figure 4. The correlation between $\mathrm{pKi}_{\mathrm{ANN}}$ and $\mathrm{pKi} \mathrm{i}_{\mathrm{obs}}$

$$
\mathrm{R}=0.955 \quad \mathrm{R}^{2}=0.912 \quad \mathrm{~S}=0.232
$$

The excellent correlation obtained with the ANN model confirms that the selected descriptors by the MLR method are relevant, and the proposed model has a high power of predictability.

\subsection{Cross-validation (CV)}

To test the effectiveness of the proposed ANN model, we used the cross-validation method using "leave one out" procedure ${ }^{32}$, keeping the same ANN architecture as used in the training set.

The predicted activities calculated by the $\mathrm{CV}$ method $\left(\mathrm{pKi}_{\mathrm{CV}}\right)$ are given in Table 1 . The correlation between pki $_{\mathrm{CV}}$ and $\mathrm{pki}_{\mathrm{obs}}$ is shown in Figure 5.

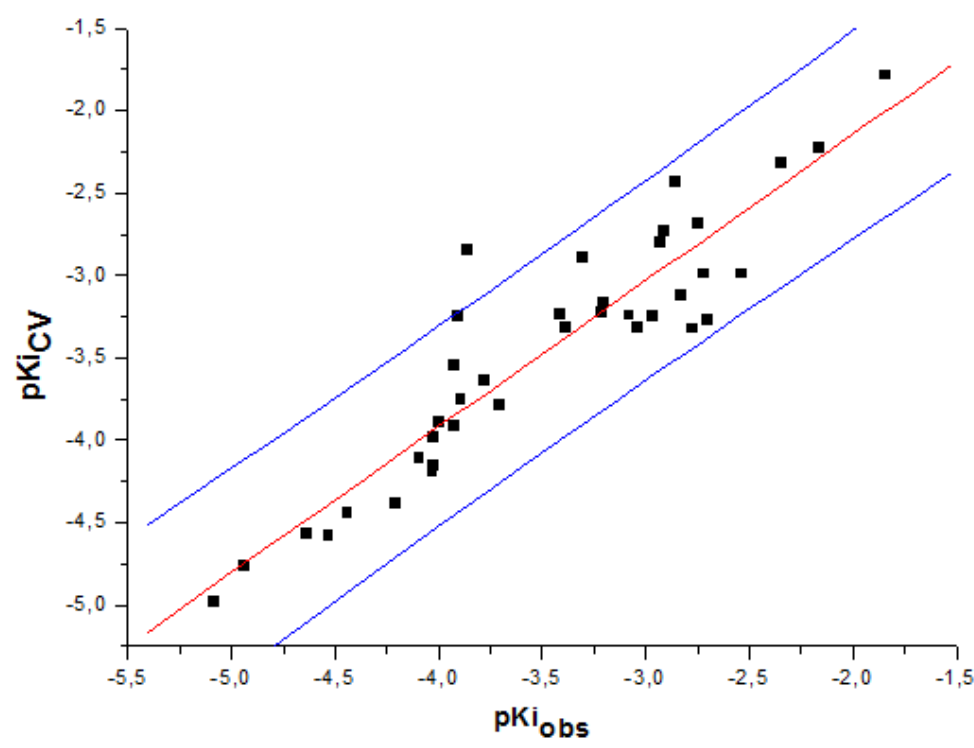

Figure 5. Correlation between $\mathrm{pKi}_{\mathrm{Cv}}$ and $\mathrm{pKi}_{\text {obs }}$

$$
\mathrm{R}_{\mathrm{cv}}=0.921 \quad \mathrm{R}^{2}=0.849 \quad \mathrm{~S}=0.305
$$

The CV predicted values show a good correlation with the observed activities, which confirms the predictive stability of the proposed model.

\subsection{Molecular docking}

To bring out the interactions of non-competitive antagonists of the NMDA receptor and to explore the geometric pharmacophore characteristics, in this part of the work we proceed to the molecular docking of the two configurations of compounds 7 and 9 .

In the case of the axial position of phenyl, the analysis of interactions with the NMDA receptor for both compounds 7 and 9, shows a hydrogen bonding 
interaction between the two hydrogen atoms of the $\mathrm{NH}_{2}$ group and the amino-acid SER B:890 at a distance of $2.05159 \AA$ and $2.22661 \AA$. On the other

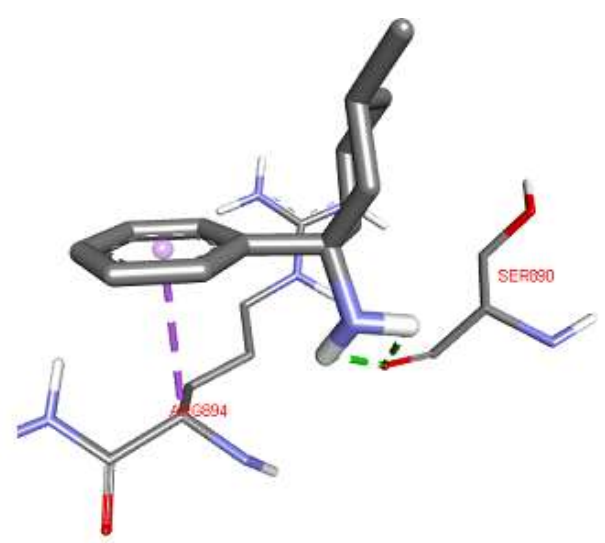

hand, a $\pi$-sigma interaction is produced between the phenyl and the amino acid ARG B:894 at a distance of 3.38849 (Figures 6 and 7).

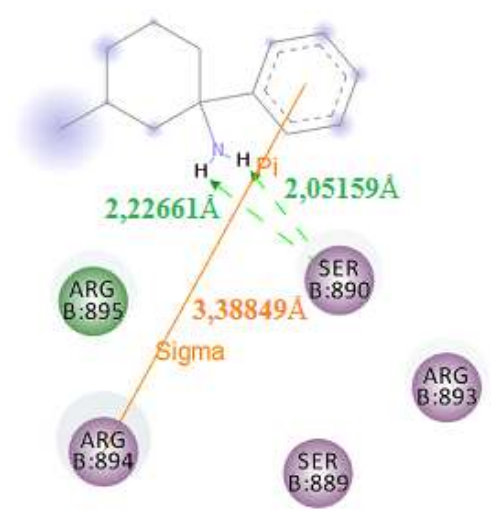

Figure 6. Molecular docking of trans7a with NMDA receptor in 3D and 2D
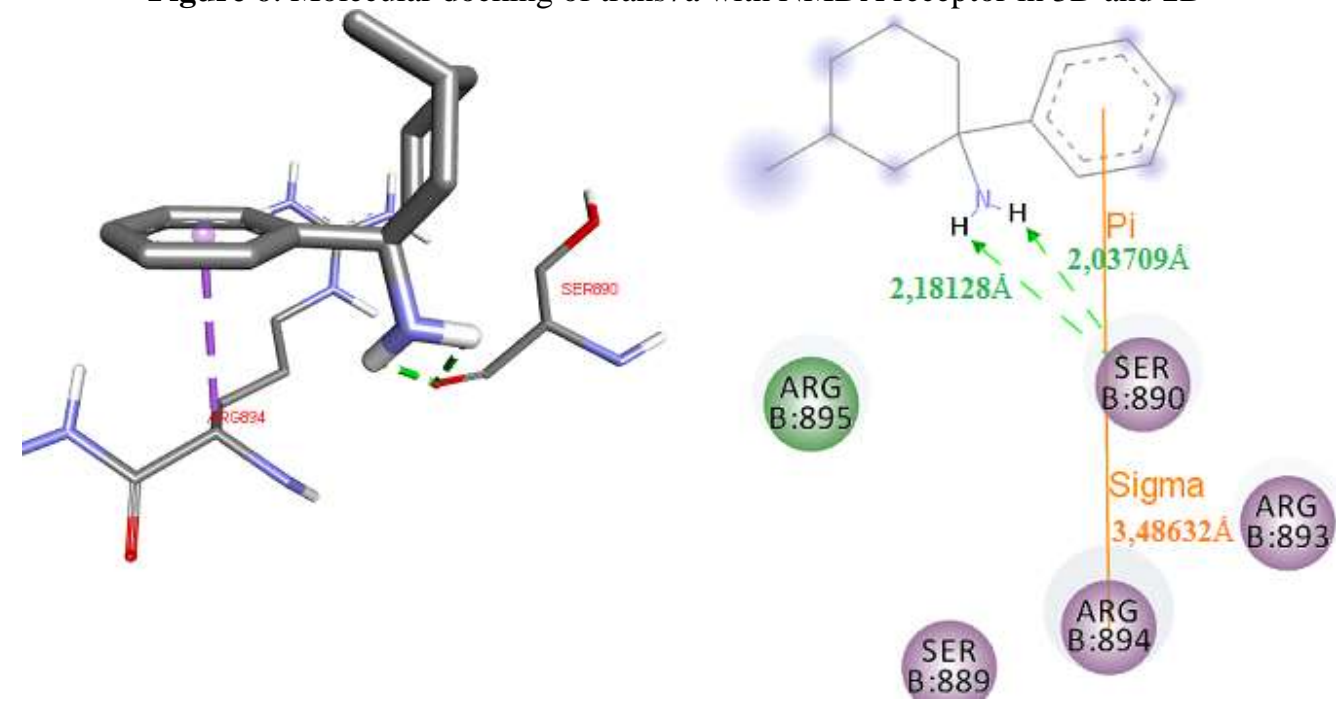

Figure 7. Molecular docking of cis9a with NMDA receptor in 3D and 2D

With the equatorial position of phenyl, the examined interactions of trans7e and cis9e show the same hydrogen bonding as with the case of axial position at almost the same distance. However, a $\pi$-sigma

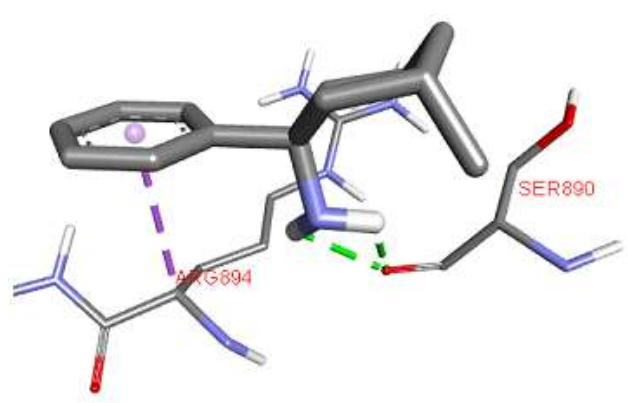

interaction between the phenyl and the ARG B: 894 amino-acid is shown with the trans7e configuration, at a distance of $3.54736 \AA$, but not for the cis9e configuration (Figures 8 and 9).

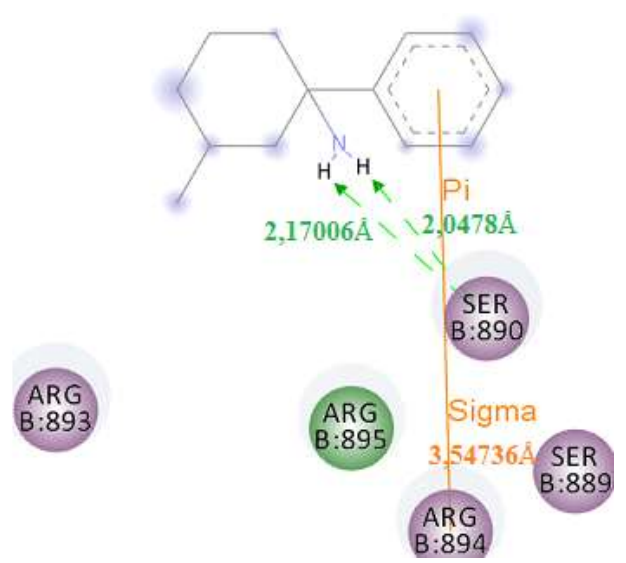

Figure 8. Molecular docking of trans7e with NMDA receptor in $3 \mathrm{D}$ and 2D 

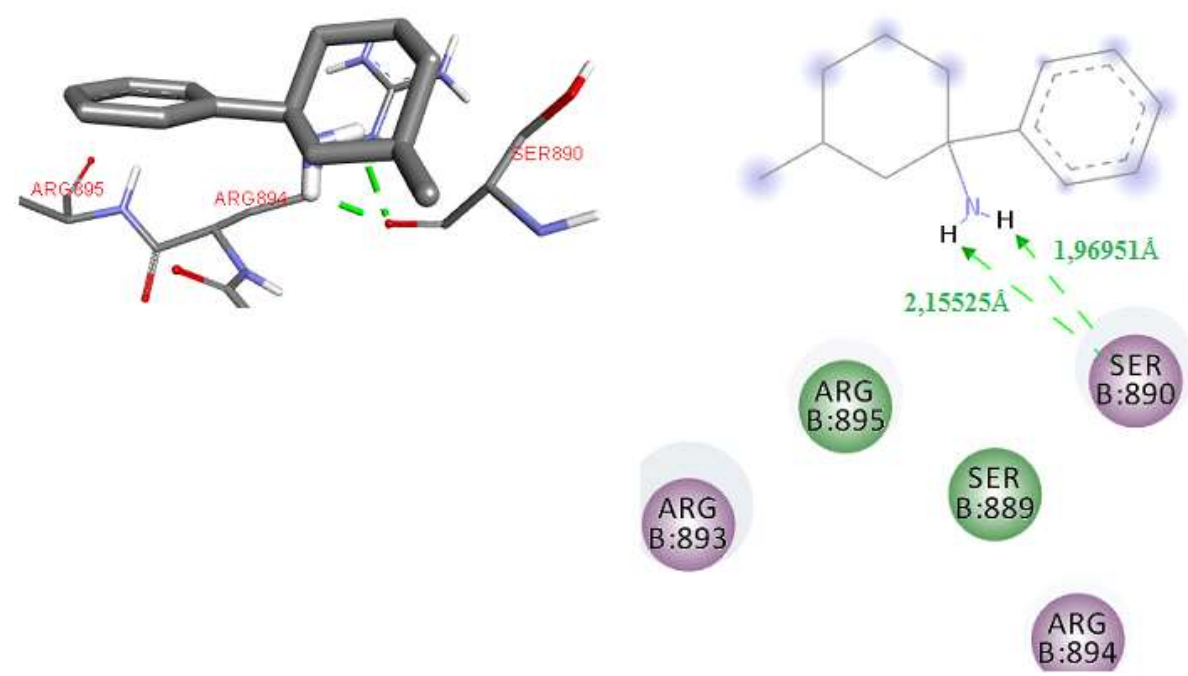

Figure 9. Molecular docking of cis9e with NMDA receptor in 3D and 2D

In summary the phenyl of the compound 9, having the lowest activity ( $\mathrm{ki}=1200 \mathrm{nM})$, doesn't form $\pi$-sigma interaction with the cis9e configuration when the phenyl adopts an equatorial position, however, it is formed for all others configurations, which let us think that it is probably to be active in the NMDA receptor, the phenyl has to adopt an axial position.
To more understand the non-interaction of phenyl adopting the equatorial position in cis9e configuration, we have proceeded to the superimposition of molecules trans7e and cis9e in the binding site of the NMDA receptor (Figure 10).

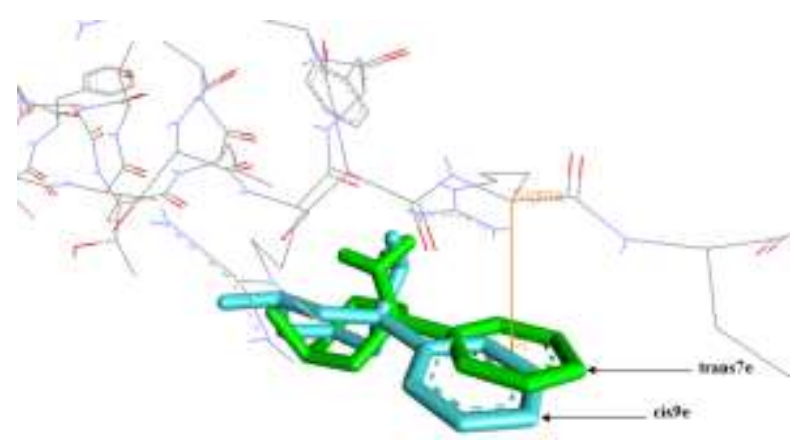

Figure 10. Superimposition of trans7e (green) and cis9e (cyan)

This superimposition reveals that the phenyl group of cis9e configuration is shifted from the binding site compared to the trans7e configuration which appears to be placed in a good position leading to the interaction of its phenyl group with ARG B:894. So we can claim that the configuration adopted by the compound 9 (cis9e) is the cause of the decrease in its activity.

\section{Conclusion}

The mathematical analysis combined to electronic computations of we have conducted to build a quantitative structure-activity relationship for noncompetitive NMDA receptor antagonists suggests that the biological activity is closely related to the Density (De) and Electrophylicity Index (Ei). These descriptors selected automatically by the multiple linear regression analysis show a high correlation with the neural network model. The $\mathrm{CV}$ test of the performance of this model confirms that the descriptors selected by the MLR method are relevant, and the proposed model presents an excellent predictive power.

The configurational analysis of compounds 7 and 9 followed by molecular docking of their different configurations with NR1 binding site showed that the same interactions ( $\pi$-sigma and hydrogen bonding) are formed for trans7a, trans7e, and cis9a. However, cis9e do not form $\pi$-sigma interaction. In attempt to explain why the phenyl group of compound 9 don't interact with NMDA receptor we have proceeded to the superimposition of cis9e to trans7e, so we observed that the phenyl group of cis9e configuration is shifted from the binding site compared to the trans7e configuration which appears to be placed in the excellent position leading to the interaction of its phenyl group with ARG B:894. So we could claim that the configuration adopted by the compound 9 (cis9e) is the cause of the decrease in its activity. 


\section{References}

1- R.G. Morris, E. Anderson, G.S. Lynch, M. Baudry, "Selective impairment of learning and blockade of long-term potentiation by an Nmethyl-d-aspartate receptor antagonist, AP5", Nature, 319, 1986, 774-776.

2- T. Kutsuwada, N. Kashiwabuchi, H. Mori, K. Sakimura, E. Kushiya, K. Araki, H. Meguro, H. Masaki, T. Kumanishi, M. Arakawa,'Molecular diversity of the NMDA receptor channel", Nature, 358, 1992, 36-41.

3- K. Nakazawa, M.C. Quirk, R.A. Chitwood, M. Watanabe, M.F. Yeckel, L.D. Sun, A. Kato, C.A. Carr, D. Johnston, M.A. Wilson, S. Tonegawa, "Requirement for hippocampal CA3 NMDA receptors in associative memory recall", Science, 297, 2002, 211-218.

4- A. Sanz-Clemente, R.A. Nicoll, K.W. Roche, "Diversity in NMDA receptor composition: many regulators, many consequences", Neuroscientist, 19, 2013, 62-75.

5- P. Paoletti, C. Bellone, Q. Zhou, "NMDA receptor subunit diversity: impact on receptor properties, synaptic plasticity and disease", Nature Reviews Neuroscience, 14, 2013, 383-400.

6- S.F. Traynelis, L.P. Wollmuth, C.J. McBain, F.S. Menniti, K.M. Vans, K.K. Ogden, K.B. Hansen, H. Yuan, S.J. Myers, R. Dingledine, "Glutamate receptor ion channels: structure, regulation, and function", Pharmacological Reviews, 62, 2010, 405-496.

7- H. Monyer, R. Sprengel, R. Schoepfer, A. Herb, M. Higuchi, H. Lomeli, N. Burnashev, B. Sakmann, PH. Seeburg, "Heteromeric NMDA receptors: molecular and functional distinction of subtype", Science, 256, 1992, 1217-1221.

8- R.A. Al-Hallaq, T.P. Conrads, T.D. Veenstra, R.J. Wenthold, "NMDA di-heteromeric receptor populations and associated proteins in rat hippocampus", Journal of Neuroscience, 27, 2007, 8334-8343.

9- S.L.C. Brothwell, J.L. Barber, D.T. Monaghan, D.E. Jane, A.J. Gibb, S. Jones, "NR2B- and NR2D-containing synaptic NMDA receptors in developing rat substantia nigra pars compacta dopaminergic neurons", Journal of Physiology, 586, 2008, 739-750.

10-M.A. Rogawski, "therapeutic potential of excitatory amino acid antagonists: channel blockers and 2,3-benzodiazepines", Trends in Pharmacological Sciences, 14, 1993, 325-331.

11-P. D. Leeson, L. L. Iversen, "The glycine site on the NMDA receptor: Structure-Activity relationships and therapeutic potential", Journal of Medicinal Chemistry, 37, 1994, 4053-4067.

12-G.L. Collingridge, A. Volianskis, N. Bannister, G. France, L. Hanna, M. Mercier, P. Tidball, G. Fang, M.W. Irvine, B.M. Costa, D.T. Monaghan, Z.A. Bortolotto, E. Molnar, D. Lodge, D.E. Jan,
"The NMDA receptor as a target for cognitive enhancement", Neuropharmacology, 64, 2013, 13-26.

13-B.M. Costa, M.W. Irvine, G. Fang, R.J. Eaves, M.B. Mayo-Martin, B. Laube, D.E. Jane, D.T. Monaghan, "Structure-activity relationships for allosteric NMDA receptor inhibitors based on 2naphthoic acid", Neuropharmacology, 62, 2012, 1730-1736.

14-B.M. Costa, M.W. Irvine, R.J. Eaves, M.B. Mayo-Martin, D.A. Skifter, D.E. Jane, D.T. Monaghan, "A novel family of negative and positive allosteric modulators of NMDA receptors", Journal of Pharmacology and Experimental Therapeutics, 335(3), 2010, 614621.

15-M.W. Irvine, B.M. Costa, A. Volianskis, G. Fang, L. Ceolin, G.L. Collingridge, D.T. Monaghan, D.E. Jane, "Coumarin-3-carboxylic acid derivatives as potentiators and inhibitors of recombinant and native N-Methyl-D-aspartate receptors", Neurochemistry International, 61, 2012, 593-600.

16-D.T. Monaghan, M.W. Irvine, B.M. Costa, G. Fang, D.E. Jane, "Pharmacological modulation of NMDA receptor activity and the advent of negative and positive allosteric modulators", Neurochemistry International, 61(4), 2012, 581592.

17-M.W. Irvine, B.M. Costa, D. Dlaboga, G. Culley, R. Hulse, C.L. Scholefield, P. Atlason, G. Fang, R. Evals, R. Morley, M.B. Mayo-Martin, M. Amici, Z.A. Bortolotto, L. Donaldson, G.L. Collingridge, E. Molnar, D.T. Monaghan, D.E. Jane, "Piperazine-2,3-dicarboxylic acid derivatives as dual antagonists of NMDA and GluK1-containing kainate receptors", Journal of Medicinal Chemistry, 55, 2012, 327-341.

18-M. Elhallaoui, M. Laguerre, A. Carpy, O.F. Chahdi, "Molecular Modeling of non-competitive antagonists of the NMDA receptor: proposal of pharmacophore and a description of interaction model", Journal of Molecular Modeling, 8, 2002, 65-72.

19-A. Thurkauf, B. Costa, S. Yamaguchi, M.V. Mattson, A.E. Jacobson, K.C. Rice, M.A. Rogawski, "Synthesis and Anticonvulsant Activity of 1-Phencyclohexylamine Analogues", Journal of Medicinal chemistry, 33, 1990, 5.

20-C.T. Lee, W.T. Yang, R.G. Parr, "Development of the Colle-Salvetti correlation-energy formula into a functional of the electron density", Physical Review B, 37, 1988, 785-789.

21-E. Niecke, P. Becker, M. Nieger, D. Stalke, W. W. Schoeller, "Carbenoid or Lithium Complex of a carbanion? Synthesis and Structure of $\left(\mathrm{Me}_{3} \mathrm{Si}\right)_{2} \mathrm{C}=\mathrm{P}(\operatorname{aryl})=\mathrm{C}(\mathrm{Cl}) \mathrm{Li}(\text { thf })_{3}$ and $\mathrm{LiCl}$ Elimination To Give the Phosphiren", Chemie International Edition in English, 34, 1995, 18491852. 
22-M.J. Frish, G. W. Turcks, H. B. Schlegel, G. E. Scuseria, M. A. Robb, J. R. Cheeseman, J. J. A. Montgomery, T. Vreven, K. N. Kudin, J. C. Burant, J. M. Millam, S. S. Lyengar, J. Tomasi, V. Barone, B. Mennucci, M. Cossi, G. Scalmani, N. Rega, G. A. Petersson, H., Hada M., Ehara M., Toyota K., Fukuda R., Hasegawa J., Ishida M., Nakajima T., Honda Y. Nakatsuji, O. Kitao, H. Nakai, M. Klene, X. Li, J. E. Knox, H. P. Hratchian, J. B. Cross, V. Bakken, C. Adamo, J. Jaramillo, R. Gomperts, R. E. Stratmann, O. Yazyev, A. J. Austin, R. Cammi, C. Pomelli, J. W. Ochterski, P. Y. Ayala, K. Morokuma, G. A. Voth, P. Salvador, J. J. Dannenberg, V. G. Zakrzewski, S. Dapprich, A. D. Daniels, M. C. Strain, O. Farkas, D. K. Malick, A. D. Rabuck, K. Raghavachari, J. B. Foresman, J. V. Ortiz, Q. Cui, A. G. Baboul, S. Clifford, J. Cioslowski, B. B. Stefanov, G. Liu, A. Liashenko, P. Piskorz, I. Komaromi, R. L. Martin, D. J. Fox, T. Keith, M. A. Al-Laham, C. Y. Peng, A. Nanayakkara, M. Challacombe, P. M. W. Gill, B. Johnson, W. Chen, M. W. Wong, C. Gonzalez, J. A. Pople, Revision D.01, Gaussian, Inc., Wallingford, CT, 2004

23-Advanced Chemistry Development Inc., Toronto, Canada (2009).

(www.acdlabs.com/resources/freeware/chemsket $\mathrm{ch} /$ ).

24-C. El M'barki, M. Elhallaoui, "Quantum Calculations to Construct a 3D-QSAR Model Based on PCP-TCP Derivatives and Molecular Docking with NMDA Receptor", Journal of Materials and Environmental Science,8 (4), 2017,1391-1400.

25-H. Hadni, M. Mazigh, E. Charif, A. Bouayad, M. Elhallaoui, Molecular Modeling of Antimalarial Agents by 3D-QSAR Study and Molecular Docking of Two Hybrids 4-Aminoquinoline- 1,3,5-triazine and 4-Aminoquinoline-oxalamide Derivatives with the Receptor Protein in Its Both Wild and Mutant Types, Biochem. Res. Int., 2018, 1-15.

26-AutoDockTools, version 1.5.6 Sep_17_14.

27-G. M. Morris, R. Huey, W. Lindstrom, M. F. Sanner, R. K. Belew, D. S. Goodsell, A. J. Olson," Autodock4 and AutoDockTools4: automated docking with selective receptor flexibility", Journal of Computational Chemistry, 16, 2009, 2785-2791.

28-Z. Akyol, L. Gakhar, B. R. Sorensen, J. H. Hell, M. A. Shea, "The NMDA Receptor NR1 C1 Region Bound to Calmodulin: Structural Insights into Functional Differences between Homologous Domains", Structure, 15, 2007, 1603-1617.

29-Discovery Studio Visualizer v4.1.0.14169 Copyright (C) 2005-14, Accelrys Software Inc.

30-H. Hadni, M. Mazigh, E. Charif, A. Bouayad, M. Elhallaoui, Molecular Modeling of Antimalarial Agents by 3D-QSAR Study and Molecular Docking of Two Hybrids 4-Aminoquinoline1,3,5-triazine and 4-Aminoquinoline-oxalamide Derivatives with the Receptor Protein in Its Both Wild and Mutant Types, Biochem. Res. Int., 2018, 1-15.

31-S. S. So, W. G. Richards, "Application of Neural Networks: Quantitative Structure-Activity Relationships of the Derivatives of 2,4-Diamino5- (substituted-benzyl) pyrimidines as DHFR Inhibitors", Journal of Medicinal Chemistry, 35, 1992, 3201-3207.

32-D. Zakarya, D. Cherqaoui, M. Esseffar, D. Villemin, J. M. Cense, “Application of Neural Networks to Structure-Sandalwood Odour Relationships", Journal of Physical Organic Chemistry, 10, 1997, 612-622. 